\title{
Evaluación de diferentes medios de cultivo en la producción in vitro de embriones bovinos
}

\author{
José Velásquez-Penagos $^{1} \bowtie$, Sonia Gutiérrez-Parrado ${ }^{1}$, Diana Barajas-Pardo ${ }^{2}$ \\ 1 Corporación colombiana de investigaciones agropecuarias, CORPOICA. Email: jvelasquez@corpoica.org.com, \\ slgutierrez@corpoica.org.co \\ 2 Universidad Cooperativa de Colombia UCC. Dianap.barajas@campusucc.edu.co
}

La producción de embriones in vitro de bovinos es una biotecnología que se viene adelantando y consolidando como una práctica cada vez mayor para la mejora de nuestras ganaderías; sin embargo, una de las preocupaciones es sobre el tema de medios y su eficiencia, en este sentido el propósito del estudio se enmarcó en probar cuatro protocolos diferenciales en las fases de maduración oocitaria (MO) y desarrollo embrionario (DE): 1. MO-(LH-Hormona Luteinizante + FSH-Hormona folículo estimulante + EGF-factor de crecimiento epidermal + IGF-factor de crecimiento insulinico + ITSinsulina transferrenina y selenio + SFB10 \%-suero fetal bovino al $10 \%$ ), DE-(SOF-fluido oviductal sintético + SFB10 \%); 2.MO-(LH + FSH + EGF + IGF + ITS + SFB5 \%), DE-(SOF + BSA-albumina sérica bovina + ITS); 3. MO-(LH + FSH + EGF + IGF + ITS + PVA-polivinil alcohol), DE-(SOF + PVA); 4.MO$(\mathrm{LH}+\mathrm{FSH}+\mathrm{SFB} 10 \%), \mathrm{DE}-(\mathrm{SOF}+\mathrm{SFB} 5 \%)$. Las variables consideradas para los 4 protocolos fueron: 1) maduración de ovocitos, 2) división a las 48 horas de fecundación y 3) producción de blastocitos. El estudio se apoyó en estadística descriptiva análisis de varianza, pruebas de Chi2. Los resultados obtenidos nos indican un comportamiento similar en las tasas de maduración de oocitos ( $\mathrm{p}>0.05)$ para los protocolos $1(78.3 \%), 2(85.00 \%), 3(85.00 \%)$ y diferente $(\mathrm{p}<0.05)$ para el protocolo $4(70.36 \%)$. Para las tasas de división a las 48 horas se observan mayores valores $(\mathrm{p}<0.05)$ para los protocolos $1(71.15$ \%) y $4(71.94 \%)$ que guardan similitud con respecto al $2(50.20 \%)$ y 3 (55.88 \%) que igualmente son similares ( $>$ >0.05). Podemos concluir que las mejores tasas de blastocitos se obtuvieron en el protocolo $1(50.82 \%)$ en forma significativa $(\mathrm{p}<0.05)$ seguido del 4,2 , y 3 . En términos integrales el estudio realizado brinda las posibilidades de cuatro protocolos para la producción de embriones.

Autor para correspondencia José Velásquez-Penagos: jvelasquez@corpoica.org.co 